\title{
DJ-I promotes survival of human colon cancer cells under hypoxia by modulating HIF-I $\alpha$ expression through the PI3K-AKT pathway
}

This article was published in the following Dove Press journal:

Cancer Management and Research

\author{
Hong Zheng',* \\ Chao Zhou ${ }^{2, *}$ \\ Xiao Lu' \\ Quanxing Liu' \\ Minqiang Liư ${ }^{2}$ \\ Guoqing Chen ${ }^{2}$ \\ Weigang Chen ${ }^{2}$ \\ Shuai Wang ${ }^{2}$ \\ Yuan Qiu
}

'Department of Thoracic Surgery of Xinqiao Hospital, The Third Military

Medical University, Shapingba, 400037,

Chongqing, People's Republic of

China; ${ }^{2}$ Department of General

Surgery of Xinqiao Hospital, The Third Military Medical University, Shapingba, 400037, Chongqing, People's Republic of China

*These authors contributed equally to this work

Correspondence: Yuan Qiu

Department of General Surgery of

Xinqiao Hospital, The Third Military

Medical University, Shapingba, Chongqing

400037, People's Republic of China

Tel +86236875 5905

Fax +862368774105

Email xiaoq2037@।26.com

Shuai Wang

Department of General Surgery of Xinqiao Hospital, The Third Military

Medical University, Shapingba, Chongqing

400037, People's Republic of China

Tel +86236875 5905

Fax +86 2368774105

Email wangshuaidoct@I26.com
Background: Protein/nucleic acid deglycase (DJ-1) and hypoxia-inducible factor-1 $\alpha$ (HIF-1 $\alpha)$ play significant roles in the progression of various types of cancer and are associated with the phosphatidylinositol 3-kinase (PI3K) pathway. However, their functions in colorectal cancer (CRC) have not been identified. The aim of this study was to analyze the putative signaling pathway encompassing DJ-1, PI3K, and HIF-1 $\alpha$ in a series of CRC tissues and cell lines.

Purpose: This study aimed at exploring the expression status of DJ-1 in colon cancer and its role in survival of cancer cell lines.

Methods: The expression and localization of DJ-1, PI3K-p110 $\alpha$, phosphorylated Akt (p-AKT), and HIF- $1 \alpha$ were determined by immunohistochemistry in 73 resected CRC tissues. The effect of DJ-1 on cell activity was explored by in vitro knockdown and overexpression experiments in SW480 and HT-29 cells. The cells were treated with a PI3K inhibitor (LY294002 or wortmannin), and p-AKT and HIF-1 $\alpha$ protein expression were then analyzed. Apoptosis was analyzed by flow cytometry. The expression levels of several HIF-1 target genes were assessed under hypoxic conditions by reverse transcription-PCR and Western blot. Xenograft tumor growth studies were conducted in DJ-1 knockdown or overexpression cells.

Results: High DJ-1 expression was found in 68.49\% (50/73) of CRC tissues and associated with larger tumor size and advanced clinical stages. DJ-1 expression was positively associated with PI3K-p1 $10 \alpha$, p-AKT, and HIF-1 $\alpha$ expression in CRC. HIF-1 $\alpha$ and p-AKT protein levels were lower in SW480 and HT-29 cells with stable DJ-1 knockdown than in those with DJ-1 overexpression. PI3K inhibitors almost completely blocked DJ-1-induced AKT phosphorylation. However, the expression of HIF- $1 \alpha$ was partially preserved after treatment with PI3K inhibitors. We also show that DJ-1 is necessary for the transcriptional ability of HIF-1 $\alpha$ and CRC cell survival after hypoxic stress. Moreover, DJ-1 promoted the growth of established tumor xenografts in nude mice.

Conclusion: Our findings are the first to show that DJ-1 is overexpressed in CRC. We suggest a model in which DJ-1 mediates CRC cell survival by regulating the PI3K-AKT-HIF-1 $\alpha$ pathway.

Keywords: DJ-1, hypoxia-inducible factor-1 $\alpha$, phosphatidylinositol 3-kinase, phosphorylated Akt, colorectal cancer

\section{Background}

Colorectal cancer (CRC) is one of the most common malignant tumors worldwide. The annual global incidence of CRC is over 1 million, and its mortality rate is as high as $33 \%$ in developed nations. ${ }^{1}$ In some Asian countries, such as China, the incidence is increasing with changing diets and lifestyles and increased lifespans. ${ }^{2}$ Despite modest improvements in multimodality therapies for $\mathrm{CRC}$, the overall prognosis of 
CRC is not optimistic, with the 5-year survival rate hovering at approximately 50\%. In recent years, a great deal of effort has been made to study the biological mechanisms underlying $\mathrm{CRC}$, and many oncogenes and tumor suppressors have recently been reported. However, the molecular mechanisms underlying the development of CRC remain poorly understood.

Hypoxia is a typical feature of solid tumors. In a hypoxic environment, responsive genes participate in the stimulation of pro-survival reactions, angiogenesis, metabolic activity alterations, tumor invasion, and metastasis. Hypoxia-inducible factor-1 (HIF-1) plays a central role in these processes. ${ }^{3}$ HIF-1 is a heterodimer that consists of two subunits: HIF-1 $\alpha$ and HIF-1 $\beta$. HIF-1 $\beta$ is constitutively expressed, whereas HIF- $1 \alpha$ is a cytoplasmic protein that responds to oxygen levels. Under non-hypoxic conditions, HIF-1 $\alpha$ is subject to rapid ubiquitination and proteasomal degradation. Therefore, total HIF-1 activity is mainly dependent on the level of HIF-1 $\alpha$ protein. ${ }^{4}$ Under hypoxic conditions, prolyl hydroxylase domains (PHDs) cannot hydroxylate the $\alpha$-subunit, resulting in $\mathrm{HIF}-1 \alpha$ protein stabilization, translocation into the nucleus, and dimerization with HIF-1 $\beta$ to form the HIF transcription factor. ${ }^{5,6}$ The activation of tyrosine kinases, such as insulin-like growth factor receptor (IGFR) and EGFR, stimulates the phosphatidylinositol 3-kinase (PI3K)/protein kinase B (AKT) signal transduction pathway, which leads to increased HIF-1 $\alpha$ expression. ${ }^{7}$ Determining the molecular processes that mediate changes in HIF-1 $\alpha$ expression will enhance our understanding of gene regulation and cancer biology and might present novel possibilities for cancer therapy.

DJ-1, also known as Parkinson's disease-associated protein 7 (PARK7), was isolated and characterized as a novel oncogene that can transform mouse NIH3T3 cells. ${ }^{8}$ In NIH3T3 cells, DJ-1 was shown to translocate from the cytoplasm to the nucleus in a cell cycle-specific manner and was hypothesized to participate in H-ras-related signal transduction events. ${ }^{8}$ Subsequent studies have shown that DJ-1 is a ubiquitous and highly conserved protein that affects cell death, proliferation, and cell cycle progression. ${ }^{9}$ DJ-1 expression can be induced by oxidative stress and is an important mediator of hypoxia-induced cellular responses. ${ }^{10}$ DJ-1 renders cells resistant to various apoptotic stimuli in a PTEN-dependent manner and prevents PTEN-induced cell death. ${ }^{11}$ DJ-1 overexpression has been reported in several malignancies, including breast and lung cancer, in which DJ-1 immunoreactivity is positively correlated with phosphorylated Akt (p-AKT) and indicates a poor prognosis. ${ }^{9}$ However, to our knowledge, no previous study has investigated the role of DJ-1 in the development of CRC.

Several studies have confirmed that DJ-1 stimulates the $\mathrm{PI} 3 \mathrm{~K} / \mathrm{Akt} / \mathrm{mTOR}$ pathway and thereby promotes cell proliferation and growth. ${ }^{12}$ In addition, the loss of DJ-1 decreases the expression level of HIF-1 $\alpha$ in neuroblastoma cells and decreases the transcription of a variety of HIF-1-responsive genes during hypoxia in human osteosarcoma cells. ${ }^{13}$ Because DJ-1 and HIF- $1 \alpha$ are correlated with PI3K/Akt, the involvement of DJ-1 and HIF- $1 \alpha$ in CRC should be clarified. In this article, we provide the first data regarding the relationship between HIF- $1 \alpha$ and DJ-1 in CRC. We demonstrate that the modulation of the DJ-1/PI3K/AKT pathway alters the expression of the HIF-1 $\alpha$ protein and HIF-1-dependent transcriptional activity. The results of this study add new insights into the capacity of DJ-1 to enhance the signaling pathways that promote tumorigenesis.

\section{Methods}

\section{Ethics statement}

Tissue specimens were obtained from CRC patients and histologically confirmed by a pathologist at the Xinqiao Hospital of the Third Military Medical University. Written informed consent was obtained from all patients, and the study was approved by the ethics committee on Human Research of Xinqiao Hospital. The care of laboratory animals was performed in full compliance with the guide for the care and use of laboratory animals of the University Committee on the use and care of animals at the Third Military Medical University, and the entire protocol was approved by this committee.

\section{Patients and tissue collection}

Seventy-three patients with CRC were included in this study. All patients underwent surgery at Xinqiao Hospital of Chongqing (Chongqing, China) between January 2012 and December 2013. The patients included 50 males and 23 females with a median age of $62.57 \pm 10.30$ years (range, 44-84 years). According to the WHO histological classification, all patients were diagnosed with $\mathrm{CRC}$ with varied tumor differentiation. None of the patients had a known history of familial polyposis syndrome or hereditary non-polyposis CRC syndrome. Carcinoma was classified according to the Union for International Cancer Control (UICC) TNM staging system. None of the patients underwent radiotherapy or chemotherapy before surgery. Tumor tissues obtained from the resected specimens and adjacent non-cancerous tissues ( $\geq 6 \mathrm{~cm}$ from the tumor) were used as normal controls (tumor and adjacent non-cancerous tissues were confirmed by the 
pathological examination). All of the above resected tissue specimens were fixed in $10 \%$ formalin and embedded in paraffin.

\section{Immunohistochemical analysis}

Tissues were fixed in 4\% paraformaldehyde and embedded in paraffin. Each tissue sample was sectioned at $4 \mu \mathrm{m}$ and mounted on poly-lysine-coated slides. Paraffin sections were deparaffinized and treated with $3 \%$ hydrogen peroxidase to block endogenous peroxidase activity. Antigen retrieval was performed in citric acid buffer $(\mathrm{pH}=6)$ in a microwave at $750 \mathrm{~W}$ for 15 minutes. After the sections were cooled, nonspecific binding of the antibody was blocked using normal cow serum. The sections were incubated with antibodies against DJ-1 (1:100, Santa Cruz Biotechnology, Inc. Dallas, TX, USA) PI3K-p110 $\alpha$ (1:200, Cell Signaling, Danvers, MA, USA), p-AKT (1:25; Cell Signaling), HIF-1 $\alpha$ (1:350; Abcam, Cambridge, MA, USA), and purified rabbit $\operatorname{IgG}(10 \mathrm{mg} / \mathrm{mL}$; negative control $[\mathrm{NC}]$ ) overnight at $4^{\circ} \mathrm{C}$. The sections were then incubated first with biotinylated goat anti-rabbit IgG for 60 minutes and then with streptavidin-enzyme conjugates (Vector Laboratories Inc., Burlingame, CA, USA). Diaminobenzidine peroxide was used as a chromogen, and hematoxylin counterstaining was performed. The sections were then dehydrated in alcohol, cleared in xylene, and mounted. An expert observer who was blinded to the experimental conditions examined the tissue sections.

Staining was graded according to the intensity and extent of epithelial staining. The extent of staining was defined as follows: 0 indicated less than 5\%; 1 indicated 5\%-25\%; 2 indicated $26 \%-50 \%$; 3 indicated $51 \%-75 \%$; and 4 indicated greater than $75 \%$. Staining intensity was scored as follows: 0 indicated no positive cells; 1 indicated weak staining; 2 indicated moderate staining; and 3 indicated strong staining. The final score was determined by multiplying the intensity of positivity score by the extent of positivity score, yielding a range from 0 to 12 . The protein expression level was considered high when the score was $\geq 6$. Immunohistochemistry results were evaluated by two independent observers who inspected all selected fields in the section to determine the percentage of cells that were positively labeled, as previously described. ${ }^{14}$

\section{Establishment of stable DJ-I- overexpression and DJ-I-knockdown SW480 and HT-29 cell lines}

The colon cancer cell lines SW480 (no. TCHu172) and HT-29 (SCSP-5032) colon cancer cell lines and the 293T (no. SCSP-502) cell line were obtained from the Shanghai
Institute for Biological Sciences, Chinese Academy of Science. To obtain the cDNA sequence of DJ-1, we amplified human DJ-1 from SW480 cell cDNA using the following primers: DJ-1 forward, 5'-AAGGAAAAAAGCGGC CGCATGGCTTCCAAAAGAGC-3'; and DJ-1 reverse, 5'-CGCGGATCCCTAGTCTTTAAGAACAAGTGGAG-3'. The PCR product was then inserted into the NotI and BamHI sites of the LV5 (EF-1a/GFP/Puro/Amp) lentiviral vector. All constructs were validated by sequencing. To establish a DJ-1 overexpression cell model, recombinant LV5 (pGLVH1/ GFP/Puro) vectors were transfected into $293 \mathrm{~T}$ cells with the three packaging plasmids pGag/Pol, pRev, and pVSV-G using Lipofectamine $^{\mathrm{TM}} 2000$ (Thermo Fisher Scientific, Waltham, MA, USA). All vectors were purchased from Sangon Biotech (Shanghai, China). At 60 hours after transfection, the virus-containing medium was collected and overlaid onto the parental cells (SW480 and HT-29) with an equal volume of fresh medium containing polybrene $(8 \mu \mathrm{g} / \mathrm{mL})$, and the cells were incubated for 48 hours. Then, the infected cells were selected with puromycin $(2.5 \mu \mathrm{g} / \mathrm{mL})$.

Stable $D J-1$ shRNA gene transfection was used to knock down $D J-1$ expression. $D J-1$ shRNA sequences were designed, synthesized, and cloned into LV-3 (pGLVH1/ $\mathrm{GFP}^{+}$Puro) vectors by Sangon Biotech. After Sangon Biotech had amplified, sequence confirmed, and tested these vectors, we purchased them for our experiments. The sequences targeting $D J-1$ shRNA were as follows: shRNA1, 5'-GGAGGTCATTACACCTACTCT-3' (DJ-1, $412 \mathrm{nt}$ ); shRAN-2, 5'-GCGCTTGCAATTGTTGAAGCC-3' (DJ-1, $499 \mathrm{nt})$; shRNA-3, 5'-GCTCAAGTGAAGGCTCCACTT-3' (DJ-1, $541 \mathrm{nt})$; and shRNA-4, 5'-GACGGTCATCCCTG TAGATGT-3' (DJ-1, $60 \mathrm{nt})$. The sequence used for the NC shRNA was 5'-TTCTCCGAACGTGTCACGT-3'. Replication-incompetent lentivirus was produced by co-transfecting the shuttle plasmid LV-3 (pGLVH1/GFP+Puro/DJ-1) and three packaging plasmids (pGag/Pol, pRev, and pVSV-G) into 293 $\mathrm{T}$ cells. At 60 hours after transfection, the virus-containing medium was collected and overlaid onto the parental cells (SW480) with an equal volume of fresh medium containing polybrene $(8 \mu \mathrm{g} / \mathrm{mL})$, and the cells were incubated for 48 hours. Then, the infected cells were selected with puromycin $(2.5 \mu \mathrm{g} / \mathrm{mL})$. The efficiency of $D J-1$ overexpression and knockdown was confirmed by Western blotting (Figure S1).

\section{RNA extraction and quantitative reverse transcription-PCR}

Total RNA was isolated from cell lines using Trizol (Thermo Fisher Scientific) according to the manufacturer's 
instructions. For each sample, $2.5 \mathrm{mg}$ of total RNA was reverse transcribed to cDNA by Super-Script III Reverse Transcriptase (Thermo Fisher Scientific). Synthesized cDNA was diluted to $10 \mathrm{ng} / \mathrm{mL}$ for all assays. Real-time quantitative PCR (q-PCR) assays were performed using the Bio-Rad CFX Connect Real-Time System (Bio-Rad Laboratories Inc., Hercules, CA, USA). SYBR ${ }^{\circledR}$ Premix Ex Taq ${ }^{\text {TM }}$ II was purchased from Takara Bio, Inc. (Shiga, Japan). The names and sequences of the primers used in this study were as follows: vascular endothelial growth factor (VEGF; forward, 5'-ACCTCCACCATGCCAAGTG-3'; and reverse, 5'-TCTCGATTGGATGGCAGTAG-3'), Bcl-2 adenovirus E1a nineteen kilodalton interacting protein 3 (BNIP3; forward, 5'-ATGTCGTCCCACCTAGTCGAG-3'; and reverse, 5'-CTCCACCCAGGAACTGTTGAG-3'), HIF-1 $\alpha$ (forward, 5'-GCCGCTGGAGACACAATCATA-3'; and reverse, 5'-GGTGAGGGGAGCATTACATCAT-3'), plasminogen activator inhibitor type-1 (PAI-1; forward, 5'-CATCCCCCATCCTACGTGG-3'; and reverse, $5^{\prime}$-CCCCATAGGGTGAGAAAACCA-3'), and $\beta$-actin (forward, 5'-CCACGAAACTACCTTCAACTCC-3'; and reverse, 5'-GTGATCTCCTTCTGCATCCTG-3'). PCR was performed with 40 cycles of denaturation at $94^{\circ} \mathrm{C}$ for 5 minutes and annealing/extension at $59^{\circ} \mathrm{C}$ for 1 minute. The cycle time to reach the threshold $(\mathrm{Ct})$ of each target gene was normalized to that of the housekeeping gene $\beta$-actin.

\section{Western blot analysis}

Nucleoproteins were extracted using a Nucleoprotein Extraction Kit (Sangon Biotech). Protein concentrations were determined according to the Bradford method using BCA assay reagent (Beyotime, Beijing, China). Samples (25 $\mathrm{mg}$ of protein) were loaded onto $8 \%-12 \%$ SDS-PAGE gels, and the proteins were then electrophoretically transferred to polyvinylidene fluoride membranes (EMD Millipore, Billerica, MA, USA). The membranes were blocked in 5\% BSA and then incubated overnight at $4{ }^{\circ} \mathrm{C}$ with the following antibodies: anti-DJ-1 (1:400; Santa Cruz), anti-HIF- $\alpha$ (1:1,000; Abcam), anti-p-AKT (1:150; Cell Signaling), anti-PI3K-p110 $\alpha$ (1:500; Cell Signaling), and anti-PCNA (1:500; Cell Signaling). After the membranes were washed, they were incubated with horseradish peroxidase (HRP)conjugated secondary antibodies (Cell Signaling) at room temperature for 1 hour. The proteins were visualized using an enhanced chemiluminescence (ECL) Kit (Amersham Life Sciences, Arlington Heights, IL, USA) and exposed using a Chemiluminescence Imaging System (Fusion Solo S, Vilber, France).

\section{Flow cytometric evaluation}

An Annexin V-APC Apoptosis Detection kit was utilized to detect early apoptosis (Annexin V-APC+/PI-, Q3), late apoptosis (Annexin V-APC+/PI+, Q2), and necrosis (Annexin V-APC-/PI+, Q1) according to the manufacturer's instructions (KFS191; Baiaolaibo, Beijing, China). Briefly, after various treatments, the cells were washed twice with cold PBS and resuspended in binding buffer at a concentration of $1 \times 10^{5}$ cells $/ \mathrm{mL}$. The cells were then first stained with Annexin V-APC for 15 minutes followed by propidium iodide for 5 minutes at room temperature in the dark. For each measurement, at least 20,000 cells were analyzed by flow cytometry using a MoFlo Cytometer (Beckman Coulter, Brea, CA, USA). All experiments were repeated three times.

\section{Cell viability and cell count analysis}

Cells were cultured in 96-well plates $(1,000$ cells in 100 $\mu \mathrm{L}$ of culture medium/well). After 24 hours, $10 \mu \mathrm{L}$ of MTT $(0.5 \mathrm{mg} / \mathrm{mL})$ was added, and the cells were incubated for 4 hours. Then, the medium was discarded, and the formazan crystals were solubilized in dimethyl sulfoxide (DMSO; Sigma-Aldrich Co., St Louis, MO, USA). Absorbance was measured at $570 \mathrm{~nm}$. Cell viability was normalized similar to that of the control group. For cell count analysis, $1.2 \times 10^{5}$ cells per well were cultured in 24 -well plates in $10 \% \mathrm{FBS}$ RPMI 1640 for 24 hours. Then, the cells were digested by tyrisin and counted using a hemocytometer.

\section{Animal study}

Female athymic BALB/c nude mice (5 weeks old) were purchased from the Laboratory Animal Center of the Third Military Medical University. The mice were housed in laminar flow cabinets under specific pathogen-free conditions. The care of laboratory animals was performed in full compliance with the guide for the care and use of laboratory animals of the University Committee at the Third Military Medical University, and the entire protocol was approved by this committee. Stably transfected SW480 and HT-29 cells and control cells $\left(5 \times 10^{6}\right)$ were injected subcutaneously (s.c.) into nude mice. Each group consisted of 6 animals. Tumors were allowed to establish for 1 week, and their sizes were then measured with calipers every 4 days for up to 7 weeks. Tumor volumes were calculated using the formula $\mathrm{V}=$ $(\text { width })^{2} \times$ length $\times 0.5$. The number of mice that died and the dates when they died were recorded to calculate the survival rate. All manipulations involving live mice were approved by the Animal Care and Use Committee of Xinqiao Hospital and performed in accordance with the Chinese Guideline of 
Welfare and Ethics for Laboratory Animals. All efforts were made to minimize suffering.

\section{Statistical analysis}

All results are expressed as the mean \pm SD. The associations between DJ-1 staining and clinicopathological parameters were analyzed using the chi-squared test. Differences between experimental groups were assessed by Student's $t$-test or one-way ANOVA. $P<0.05$ was considered statistically significant. All experiments were repeated three times. Statistical and study data were analyzed using GraphPad software (GraphPad Prism version 6.0 for Windows; GraphPad Software, Inc., La Jolla, CA, USA).

\section{Results}

\section{Expression of DJ-I, PI3K-pI I0 $\alpha, \mathrm{p}-\mathrm{AKT}$, and HIF-I $\alpha$ in CRC tissues}

The expression and localization of DJ-1, PI3K-p110 $\alpha$, p-AKT, and HIF- $1 \alpha$ were determined by immunohistochemistry in 73 resected CRC tissues. Staining for each protein is shown in a representative clinical sample in Figure 1. Among the $73 \mathrm{CRC}$ specimens, DJ-1 and HIF-1 $\alpha$ were highly expressed in $68.49 \%$ (50/73) and $73.97 \%$ (54/73), respectively. The localization of DJ-1 and HIF-1 $\alpha$ was mostly cytoplasmic with some nuclear staining. Conversely, no or weak staining for these proteins was detected in the corresponding normal tissues. Strong p-AKT, expression was more frequently observed in cancerous tissues than in normal tissues. Similarly, PI3K-p110 $\alpha$ expression was higher in tumor tissues than in non-tumor tissues. Furthermore, the associations between DJ-1 expression and the clinicopathological features of patients were investigated (Table 1). High DJ-1 expression was significantly associated with larger tumor size $(P=0.04)$. Moreover, late stage cancer patients exhibited significantly higher levels of DJ-1. Association analyses showed that there was a significant association between DJ-1 expression and gender $(P=0.029)$. However, there was no significant association between DJ-1 expression and patient age or tumor differentiation.

To determine how DJ-1 might be involved in CRC progression, we investigated the correlations between the expression of DJ-1 and its possible downstream effectors, including PI3K and p-AKT. As shown in Table 2, in CRC tissues, there were significantly positive correlations between DJ-1 and PI3K-p110 $\alpha$ expression $(r=0.546, P<0.001)$ and between DJ-1 and p-AKT expression $(r=0.530, P=$ 0.001). Moreover, closer observation of immunoreactivity for DJ-1 and HIF- $1 \alpha$ indicated that tumor cells with DJ-1 expression also expressed high levels of HIF- $1 \alpha(r=0.606$, $P<0.001)$. The above data show that DJ-1 is upregulated in CRC and suggest that it may regulate HIF- $1 \alpha$ in a PI3K/ Akt-dependent manner.

\section{DJ-I promotes survival of human colon cells under hypoxic conditions}

To investigate whether DJ-1 expression is involved in the colon cancer cell survival under hypoxic conditions, SW480
A

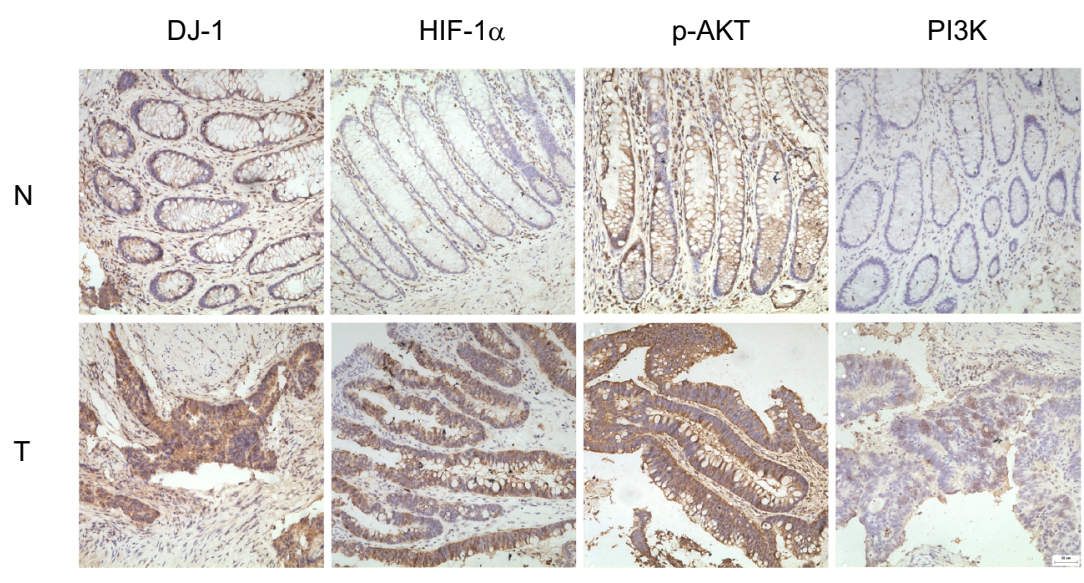

B

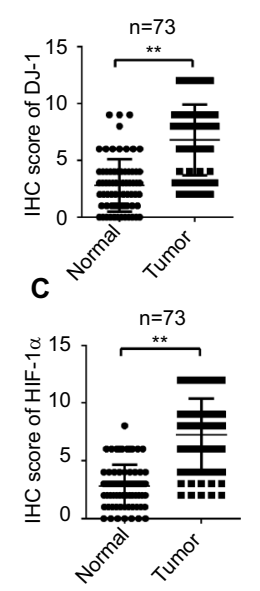

Figure I Expression of DJ-I, HIF-I, P-AKT, and PI3K in CRC and adjacent tissue.

Notes: (A) Immunohistochemical staining of DJ-I, PI3K, p-AKT, and HIF-I $\alpha$ in CRC and adjacent normal tissues. First row, adjacent normal tissues (N); second row, tumor tissues (T). Images: 200x magnification. (B) DJ-I IHC scores of tumors and adjacent normal tissues from 73 paired CRC specimens. (C) HIF-I $\alpha$ IHC scores of tumors and adjacent normal tissues from 73 paired $C R C$ specimens. ${ }^{* *} P<0.01$.

Abbreviations: CRC, colorectal cancer; HIF-I $\alpha$, hypoxia-inducible factor-I $\alpha$; IHC, immunohistochemistry; p-AKT, phospho-Akt; PI3K, phosphatidylinositol 3-kinase. 
Table I Associations of tumor characteristics with DJ-I expression in colorectal cancer

\begin{tabular}{|c|c|c|c|c|}
\hline \multirow[t]{2}{*}{ Tumor characteristics } & \multirow[t]{2}{*}{$\mathbf{N}(\%)$} & \multicolumn{3}{|c|}{ DJ-I expression } \\
\hline & & Low & High & $P$ \\
\hline Over all & $73(100)$ & 23 & 50 & \\
\hline \multicolumn{5}{|l|}{ Age (years) } \\
\hline$\leq 60$ & $33(45.20)$ & 7 & 26 & \\
\hline$>60$ & $40(55.80)$ & 16 & 24 & 0.293 \\
\hline \multicolumn{5}{|l|}{ Gender } \\
\hline Male & $50(68.49)$ & 20 & 30 & \\
\hline Female & $23(3 \mid .5 I)$ & 3 & 20 & 0.029 \\
\hline \multicolumn{5}{|l|}{ Differentiation degree } \\
\hline Well and moderate & $47(64.38)$ & 13 & 34 & \\
\hline Poor & $26(35.62)$ & 10 & 16 & 0.432 \\
\hline \multicolumn{5}{|l|}{ Tumor size $(\mathrm{cm})$} \\
\hline$\leq 3$ & $28(38.36)$ & 13 & 15 & \\
\hline$>3$ & $45(61.64)$ & 10 & 35 & 0.040 \\
\hline \multicolumn{5}{|l|}{ Stage } \\
\hline I-II & $44(60.28)$ & 18 & 26 & \\
\hline III-IV & $29(29.72)$ & 4 & 24 & 0.020 \\
\hline
\end{tabular}

Notes: All data were analyzed by using chi-squared test. $P<0.05$ was considered to be significant.

Table 2 Associations of HIF-I $\alpha$, PI3K, and p-AKT expression with DJ-I expression in colorectal cancer

\begin{tabular}{|c|c|c|c|c|}
\hline \multirow[t]{2}{*}{ Gene } & \multirow[t]{2}{*}{ n (\%) } & \multicolumn{3}{|c|}{ DJ-I expression } \\
\hline & & Low & High & $P$ \\
\hline \multicolumn{5}{|c|}{ HIF-I $\alpha$ expression } \\
\hline Low & $19(26.03)$ & 15 & 4 & $r=0.606$ \\
\hline High & $54(73.97)$ & 8 & 46 & 0.000 \\
\hline \multicolumn{5}{|c|}{ PI3K expression } \\
\hline Low & $21(28.77)$ & 15 & 6 & $r=0.546$ \\
\hline High & $52(71.23$ & 8 & 44 & 0.000 \\
\hline \multicolumn{5}{|c|}{$p-A K T$ expression } \\
\hline Low & $24(32.88)$ & 16 & 8 & $r=0.530$ \\
\hline High & $49(67.12)$ & 7 & 42 & 0.001 \\
\hline
\end{tabular}

Notes: All data were analyzed by using chi-squared test. $P<0.05$ was considered to be significant.

Abbreviations: HIF-I $\alpha$, hypoxia-inducible factor-I $\alpha$; p-AKT, phospho-Akt; PI3K, phosphatidylinositol 3-kinase.

and HT-29 cells with stable DJ-1 overexpression or knockdown were established (Figure S1), and flow cytometry was performed to detect apoptosis after hypoxia $\left(2 \% \mathrm{O}_{2}, 12\right.$ hours) was induced. As shown in Figure 2A, D, apoptosis in SW480 (15.2 \pm 2.5$)$ and HT-29 (14.9 \pm 2.1$)$ cells with DJ-1 knockdown was double that observed in control SW480 and HT-29 cells, respectively. Furthermore, DJ-1 overexpression significantly inhibited apoptosis in SW480 (1.11 \pm 0.4$)$ and HT-29 (2.38 \pm 1.1$)$ cells. An MTT analysis and cell counts showed that DJ-1 knockdown decreased cell viability (Figure 2B, E) and cell proliferation (Figure 2C, F) in SW480 and HT-29 cells. These results indicate that overexpressing
DJ-1 may promote colon cancer cell survival under hypoxic conditions.

\section{DJ-I promotes HIF-I $\alpha$ expression through a PI3K/Akt-dependent mechanism}

Because DJ-1 expression was positively correlated with HIF-1 $\alpha$ expression in CRC tissues, we next evaluated HIF-1 $\alpha$ expression in SW480/HT-29-DJ-1 ${ }^{-/}$and SW480/ HT-29-DJ-1 ${ }^{+/+}$cells under both normoxia $\left(21 \% \mathrm{O}_{2}\right)$ and hypoxia $\left(2 \% \mathrm{O}_{2}, 12\right.$ hours). The mRNA levels of HIF-1 $\alpha$ were measured by q-PCR. As shown in Figure 3A, D, in 
A

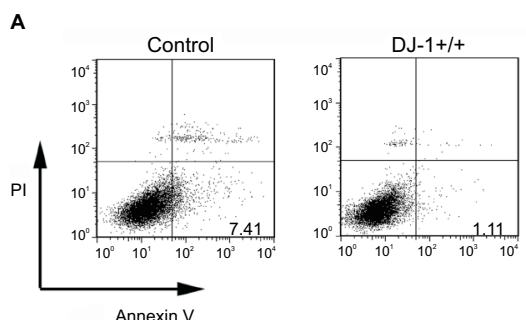

Annexin V
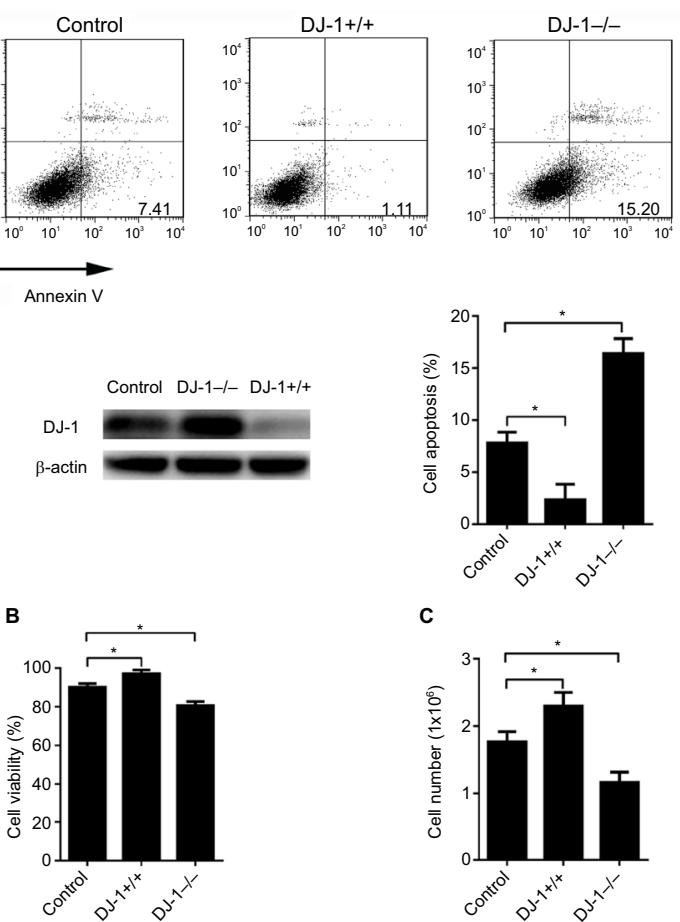

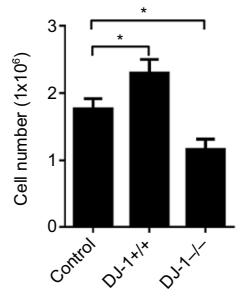

D
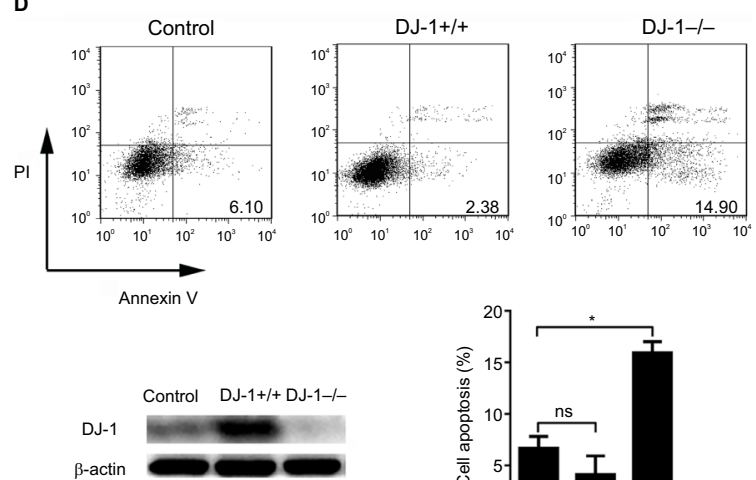

E

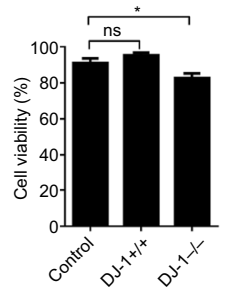

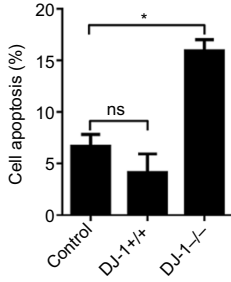

$\mathbf{F}$

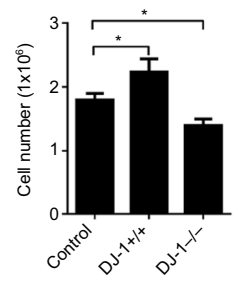

Figure 2 DJ-I knockdown induced cell apoptosis in colon cancer cells.

Notes: DJ-I stable overexpression and knockdown SW480/HT-29 cells were established and cultured in hypoxia ( $2 \% \mathrm{O}_{2}, 12$ hours). Western blot was used to detect the DJ-I protein level during hypoxia. (A, D) Apoptosis analysis, (B, E) MTT, and (C, F) cell count experiments were used to analyze the apoptosis, viability, and proliferation of SW480/HT-29-DJ-I ${ }^{+/+}$, SW480/HT-29-DJ-I ${ }^{-1-}$ and parental SW480/HT-29 cells. Data shown are the mean fold induction \pm SD. $* P<0.05$. The experiments were repeated three times.

Abbreviation: ns, no significant statistical difference.

the normoxia-treated cells, there was a relatively small or negligible difference in HIF-1 $\alpha$ mRNA levels between the cells. Furthermore, there was no significant difference in HIF- $1 \alpha$ mRNA levels between the cells incubated under hypoxic conditions. However, the protein level of HIF-1 $\alpha$ in the cytoplasm and nucleus was significantly lower in the DJ-1-knockdown cells than in the control cells under all tested conditions (Figure 3B, E). In our previous studies, we found dramatically increased HIF-1 $\alpha$ protein expression in cells incubated under hypoxic conditions for 12 hours. Therefore, these hypoxic conditions were chosen for subsequent experiments. ${ }^{15}$

To investigate whether the PI3K pathway activity is associated with the changes in HIF-1 $\alpha$ expression induced by DJ-1, we exposed SW480/HT-29-DJ-1 ${ }^{-/}$, SW480/ HT-29-DJ-1 ${ }^{+/+}$, and control cells to the PI3K inhibitors LY294002 $(10 \mu \mathrm{M})$ and wortmannin $(100 \mathrm{nM})$. At 12 hours after the PI3K inhibitors were added, HIF-1 $\alpha$ protein levels were assessed by Western blotting. As shown in Figure 3C, $\mathrm{F}$, in SW480/HT-29-DJ-1 ${ }^{-/}$and control cells treated with LY294002 or wortmannin, HIF-1 $\alpha$ expression was almost completely blocked, whereas both inhibitors had a diminished effect on HIF-1 $\alpha$ expression in the SW480/HT-29-DJ-1 ${ }^{+/+}$ group. AKT resides between PI3K and HIF- $1 \alpha$ in this signaling pathway. A modest degree of AKT phosphorylation was detected in control cells, and this amount was decreased in response to DJ-1 deficiency. The extent of AKT phosphorylation was greater in SW480/HT-29-DJ- $1^{+/+}$cells than in control cells and was blocked by PI3K inhibitors. Total AKT protein levels were not affected by DJ-1, LY294002, or wortmannin. Taken together, these results suggest that the PI3K/Akt signal transduction pathway is required for the DJ-1-induced expression of HIF- $1 \alpha$ in CRC cells.

\section{DJ-I is essential for HIF-I $\alpha$ target gene expression}

To investigate the mechanism by which HIF-1 $\alpha$ transcriptional activity is regulated by DJ-1, we detected HIF-1 $\alpha$ downstream target genes. We subjected SW480/ HT-29-DJ-1 ${ }^{-/}$, SW480/HT-29-DJ-1 ${ }^{+/+}$, and control cells to hypoxia for 12 hours and then assayed VEGF, BNIP3, and PAI-1 mRNA expression using q-PCR. As shown in Figure 
A

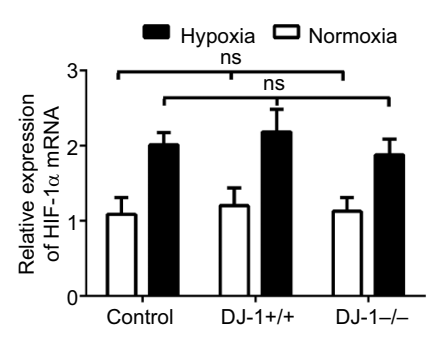

B

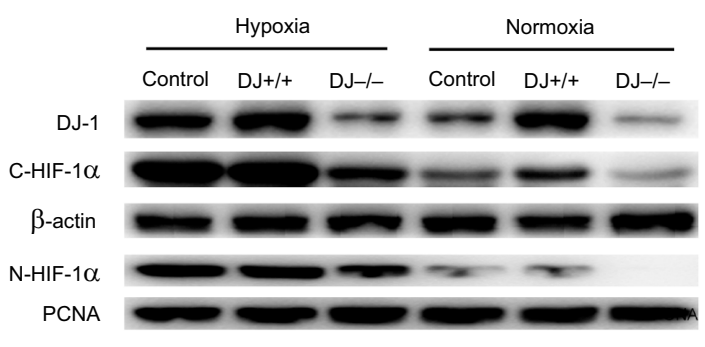

C

SW480

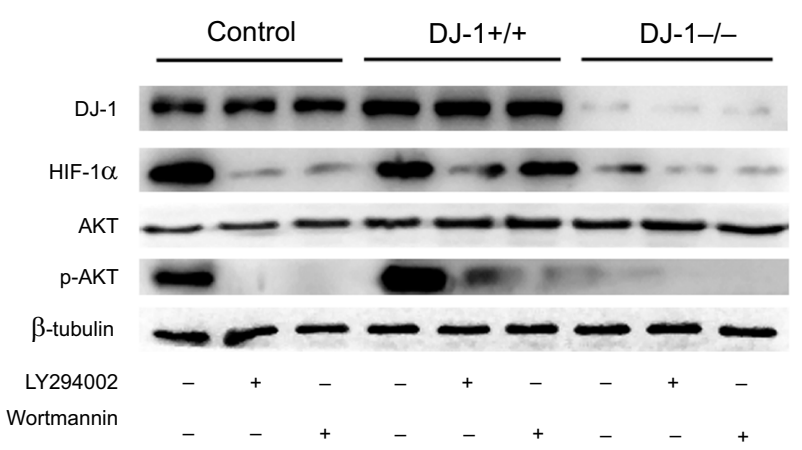

D

HT-29

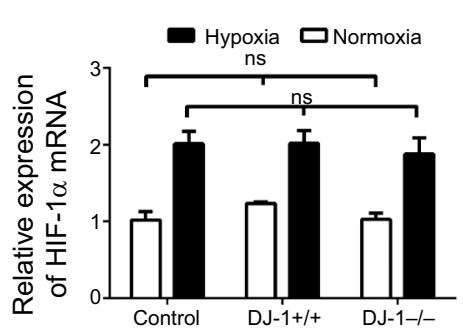

E

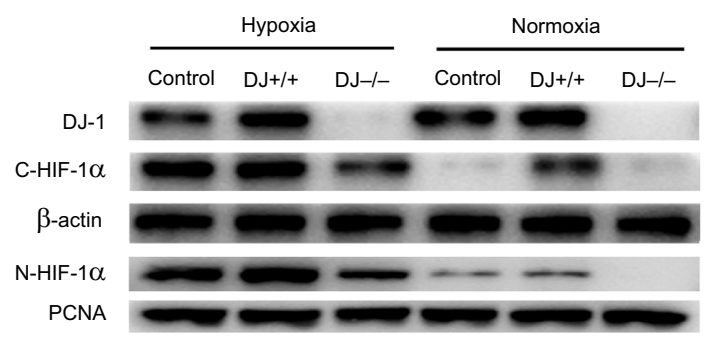

F

HT-29

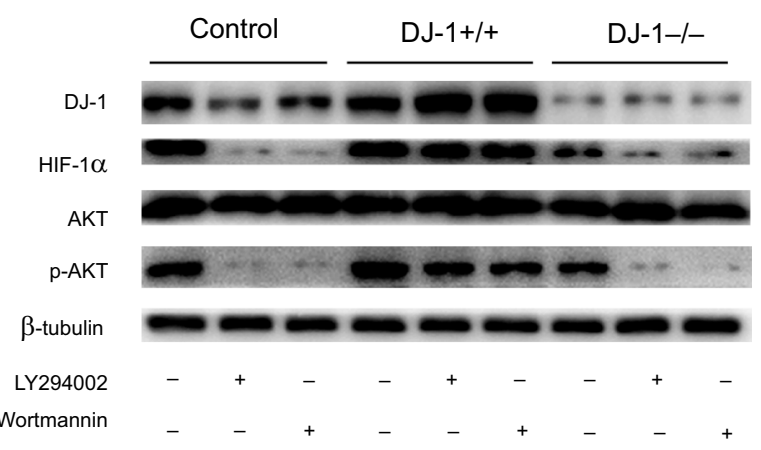

Figure 3 Effects of DJ-I knockdown and overexpression on HIF-I $\alpha$ expression and AKT phosphorylation.

Notes: Parental SW480/HT-29, SW480/HT-29-DJ-I $\mathrm{I}^{-1-}$, and SW480/HT-29-DJ-1 $\mathrm{I}^{+/+}$cells in six-well plates were cultured under either normoxic $(21 \%$ O $)$ or hypoxic $(2 \%$ $\mathrm{O}_{2}, 12$ hours) conditions. mRNA levels of HIF-I $\alpha$ were determined by RT-PCR. Protein levels of DJ-I, HIF-I $\alpha$, AKT, and p-AKT were determined by Western blot. (A, D) The mRNA expression levels of HIF-I $\alpha$ in parental SW480/HT-29, SW480/HT-29-DJ-I ${ }^{-1-}$, and SW480/HT-29-DJ-I ${ }^{+/+}$cells. Data shown are the mean fold induction \pm SD of mRNA compared to base expression as determined using control SW480/HT-29 cells. (B, E) The protein levels of C-HIF-I $\alpha$ (cytoplasm) and N-HIF-I $\alpha$ (nucleus) in parental SW480, SW480/HT-29-DJ-I-1-, and SW480/HT-29-DJ- $\mathrm{I}^{+/+}$cells. (C, F) Parental SW480/HT-29, SW480/HT-29-DJ-I ${ }^{-1-}$, and SW480/HT-29-DJ-I ${ }^{+/+}$cells were treated separately with the PI3K inhibitor LY294002 (I0 $\mu \mathrm{M})$ or wortmannin ( $100 \mathrm{nM})$ in hypoxic condition, and cells were collected and analyzed by immunoblotting after 12 hours. The experiments were repeated three times.

Abbreviations: HIF-I $\alpha$, hypoxia-inducible factor-I $\alpha$; p-AKT, phospho-AKT; PI3K, phosphatidylinositol 3-kinase; ns, no significant statistical difference; RT-PCR, reverse transcription-PCR; PCNA, proliferating cell nuclear antigen.

4A, B, the mRNA expression levels of VEGF, BNIP3, and PAI-1 were significantly higher in SW480/HT-29-DJ-1+/+ cells than in control cells. DJ-1 knockdown significantly reduced the mRNA expression levels of HIF-1 $\alpha$ target genes by an average of 4.7-fold in SW480 cells and 4.5-fold in HT-29 cells. Similar reductions were observed for the PAI-1 mRNA and the protein levels of all three factors. These data, in combination with those shown in Figure 2, demonstrate that DJ-1 could be associated with CRC cell resistance to hypoxic stress.

\section{DJ-I promotes in vivo colon cancer growth}

A xenograft study was established by injecting nude mice with SW480 and HT-29 cells. Xenograft tumor growth was studied using a tumor growth curve. From this growth curve, 
A

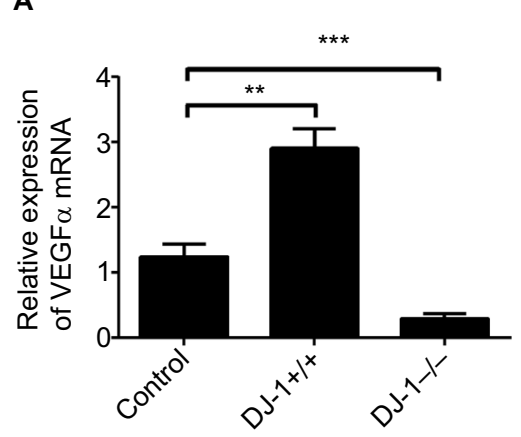

$$
\text { Control DJ+/+ DJ-/- }
$$

VEGF $\alpha$

$\beta$-actin
SW480

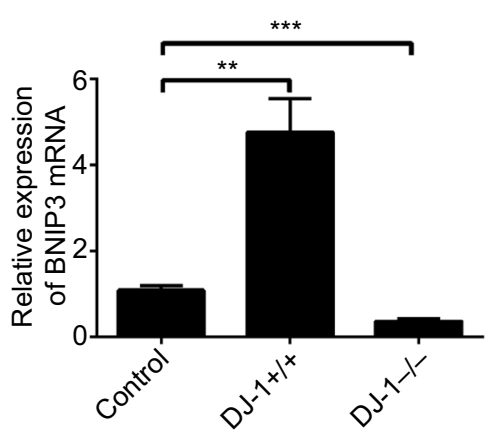

Control DJ+/+ DJ-/-

BNIP3

$\beta$-actin

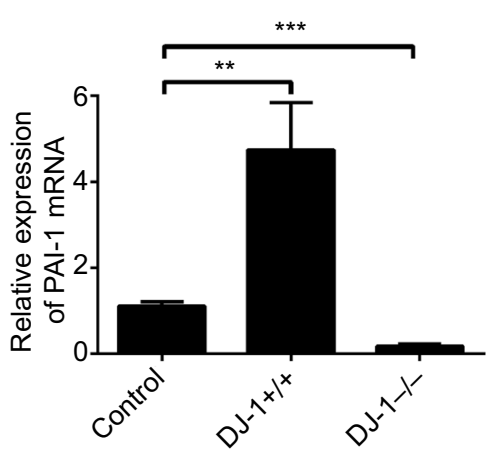

Control DJ+/+ DJ-/-

PAI-1

$\beta$-actin

B

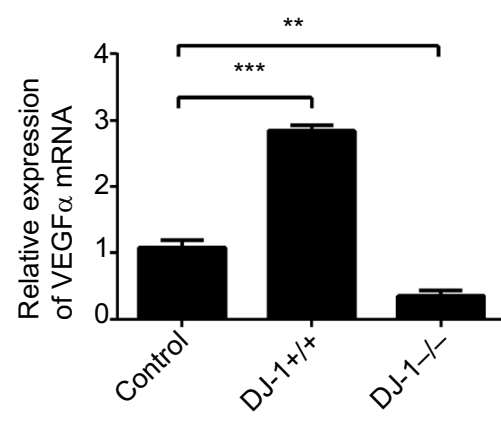

$$
\text { Control DJ+/+ DJ-/- }
$$

VEGF $\alpha$

$\beta$-actin

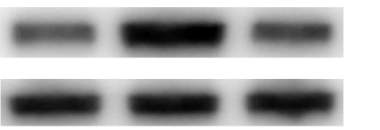

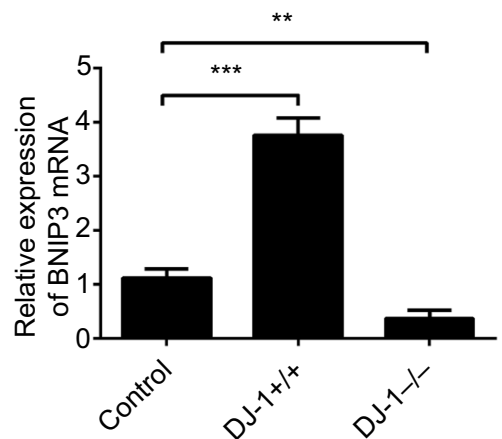

Control DJ+/+ DJ-/-

BNIP3

$\beta$-actin
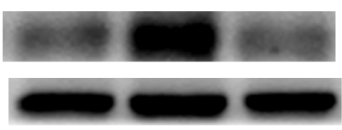

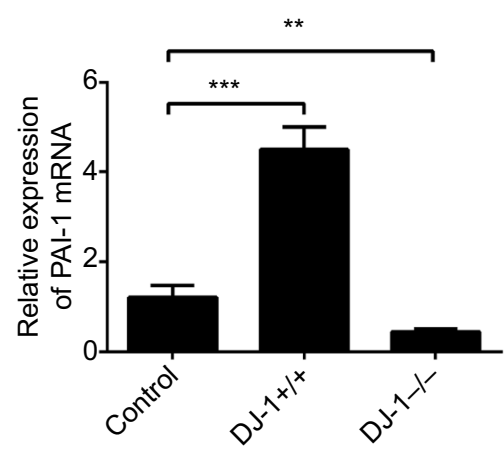

Control DJ+/+ DJ-/-

PAI-1

$\beta$-actin

Figure 4 Effects of DJ-I knockdown and overexpression on HIF-I $\alpha$ target gene expression.

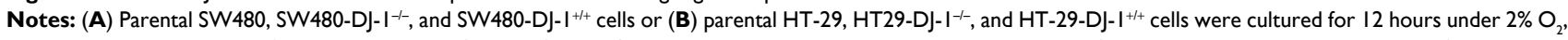
and the transcription levels of the target genes VEGF, BNIP3, and PAI-I were determined by quantitative real-time RT-PCR analysis. Data shown are the mean fold induction \pm SD of mRNA compared to base expression, as determined using control SW480 cells under hypoxia. Protein levels of the target genes were determined by Western blot. Data shown are the mean fold induction $\pm S D$ of mRNA compared to base expression determined using $W T$. $* * P<0.01$, and $* * * P<0.001$. Results shown are representative of at least three independent experiments.

Abbreviations: BNIP3, Bcl-2 adenovirus Ela nineteen kilodalton interacting protein 3; HIF-I $\alpha$, hypoxia-inducible factor-I $\alpha$; PAI-I, plasminogen activator inhibitor type-I; VEGF, vascular endothelial growth factor; RT-PCR, reverse transcription-PCR; WT, wild type cells.

we found that the tumor volume was much higher in the DJ-1 overexpression group $\left(1,111.14 \pm 283.78 \mathrm{~mm}^{3}\right)$ than in the DJ-1 knockdown $\left(256.67 \pm 67.83 \mathrm{~mm}^{3}\right)$ and control $\left(599.68 \pm 108.09 \mathrm{~mm}^{3}\right)$ groups of SW480 cells (Figure 5A). Moreover, in HT-29 cells, the tumor volume was larger in the DJ-1 overexpression group $\left(1,033.33 \pm 162.58 \mathrm{~mm}^{3}\right)$ than in the DJ-1 knockdown $\left(306.67 \pm 72.33 \mathrm{~mm}^{3}\right)$ and control $\left(616.67 \pm 52.14 \mathrm{~mm}^{3}\right)$ groups (Figure 5D). An analysis of survival ratios showed that DJ-1 overexpression or knockdown was associated with tumor volume (Figure 5B, E). Furthermore, the tumor doubling times in the SW480 and HT-29 cells in the DJ-1 overexpression group were 4 days 
A

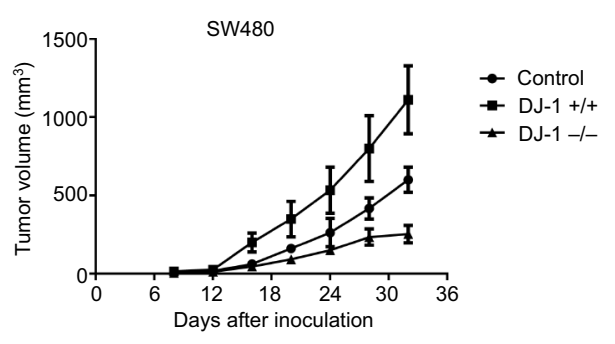

D

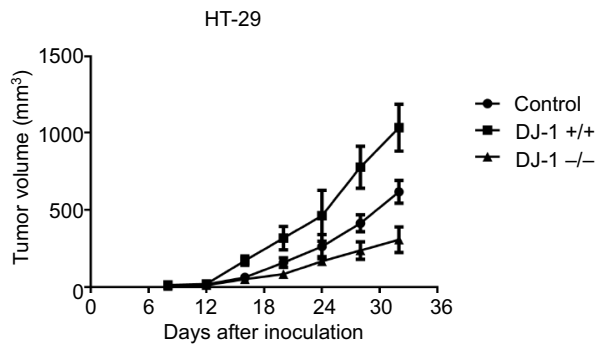

B

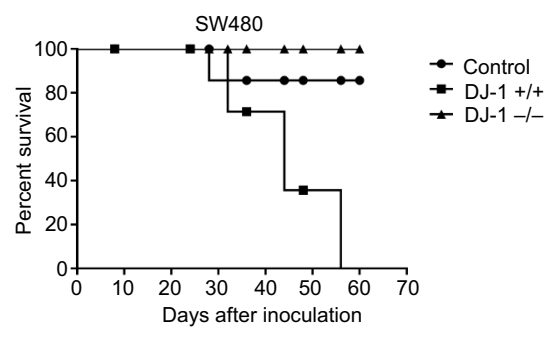

E

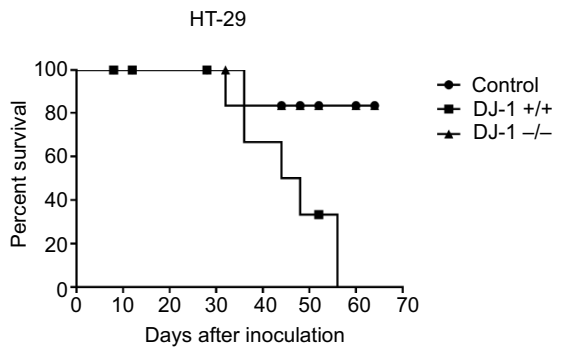

C

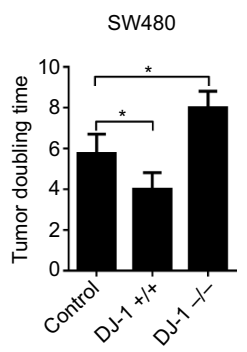

$\mathbf{F}$ HT-29

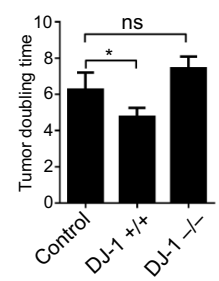

Figure 5 Effects of $\mathrm{DJ}-\mathrm{I}$ knockdown and overexpression on tumor growth and mouse death.

Notes: The stably transfected (A) SW480 and (D) HT-29 cells and control cells $\left(5 \times 10^{6}\right)$ were injected s.c. into nude mice. Tumors were allowed to establish for I week, and then sizes were measured with calipers every 4 days for up to 7 weeks. (B, E) Survival curves of mice. Data were analyzed by the log-rank test. (C, F) Tumor doubling time. Data are presented as the mean $\pm S D(* P<0.05)$. The experiments were repeated three times.

Abbreviations: s.c., subcutaneous; ns, no significant statistical difference.

and 4.75 days, respectively (Figure 5C, F). Interestingly, there was no difference in xenograft tumor growth between the DJ-1 overexpression group and the control group at an early stage, such as at 15 days $(P>0.05)$.

\section{Discussion}

In this study, we show that DJ-1 regulates HIF- $1 \alpha$ and promotes cell survival via the PI3K/AKT pathway. The Parkinson's disease-associated protein DJ-1 was recently reported to participate in different intracellular signaling pathways to protect cancer cells from apoptotic stimuli. DJ-1 is overexpressed in various malignant tissues, including breast, lung, ovary, and esophageal carcinomas. ${ }^{16-18}$ DJ-1 is also a prognostic factor that predicts poor outcomes in cancer patients. ${ }^{19,20}$ However, the DJ-1 expression status in CRC had not been previously reported. In this study, we analyzed DJ-1 protein expression in primary CRC samples. We found that DJ-1 was expressed in 50 of $73(68.5 \%)$ CRC specimens. Nuclear DJ-1 expression was strong in tumor cells but relatively lower in normal epithelial cells. Several lines of evidence suggest that DJ-1 plays diverse roles in various subcellular compartments. For instance, DJ-1 plays important roles in the antioxidative functions of mitochondria, ${ }^{21,22}$ and nuclear DJ-1 might interact with other transcription cofac- tors to modify their transcriptional activity. ${ }^{23}$ In addition, a high level of DJ-1 was closely associated with tumor size and a higher clinical stage, suggesting that DJ-1 might play a role in accelerating CRC progression. The present results support the previous conclusion that high levels of DJ-1 are correlated with more aggressive clinical behaviors in some neoplasms. ${ }^{24,25}$

DJ-1 upregulation in response to oxidative insult is considered important for neuroprotection. The absence of this response leads to dopaminergic neuron degeneration in Parkinson's disease. ${ }^{26}$ A potential mechanism underlying this effect might involve the ability of DJ-1 to inhibit HIF-1 $\alpha$ degradation in hypoxia. ${ }^{27}$ Recently, the expression of DJ-1 in cancer cells was experimentally demonstrated to protect the cells from hypoxia-induced apoptosis. ${ }^{28}$ This protection might be particularly important for carcinogenesis and cancer cell survival. Thus, we focused on HIF-1 $\alpha$, a major regulator of angiogenesis, carcinogenesis, and various processes used by cells to adapt to hypoxic conditions. ${ }^{29} \mathrm{We}$ found that HIF-1 $\alpha$ was expressed in 54 of $73(74.0 \%)$ CRC specimens. Moreover, we show that DJ-1 expression is positively correlated with HIF-1 $\alpha$ expression in CRC specimens. These results indicate that there may be an interaction between DJ-1 and HIF-1 $\alpha$ in tumor cells. Recent studies have shown that 
HIF- $1 \alpha$ protein stability and activation are also influenced by oxygen-independent mechanisms involving growth factors, tumor suppressors, and deregulated oncogenes. It is worth noting that the increased stability of the HIF- $1 \alpha$ protein is regulated in part by the PI3K/AKT pathway. ${ }^{30}$ In this study, we found that PI3K was expressed at high levels in tumor tissues and that a high level of AKT phosphorylation was closely associated with an increase in the expression of DJ-1. Consistent with these results, recent studies have shown that DJ-1 acts as a PTEN antagonist and may promote oncogenesis by activating the PI3K/AKT pathway. ${ }^{10,31}$ These data strongly support the notion that DJ-1 plays a role in regulating the expression of HIF-1 $\alpha$ in CRC cells via the $\mathrm{PI} 3 \mathrm{~K} / \mathrm{AKT}$ pathway.

Given these links between PI3K/AKT and HIF-1 $\alpha$ and our observation that DJ-1 may influence PI3K/AKT pathway activity, we sought to confirm that the DJ-1-induced effects on the PI3K/AKT pathway play a critical role in HIF-1 $\alpha$ expression and/or stability in vitro. Thus, we used shRNA to generate DJ-1-knockdown SW480/HT-29 cells (SW480/ HT-29-DJ-1 ${ }^{--}$), and we then used the EF-1a/GFP/Puro/Amp lentivirus vector to generate DJ-1-overexpressing SW480/ HT-29 cells (SW480/HT-29-DJ-1 ${ }^{+/+}$). Western blot analysis showed that HIF-1 $\alpha$ and p-AKT levels were higher in SW480/ HT-29-DJ- $1^{+/+}$cells than in SW480/HT29-DJ-1 $1^{-/}$and SW480 cells. Interestingly, the HIF-1 $\alpha$ mRNA level was unchanged in each group, suggesting that DJ-1 overexpression posttranscriptionally upregulates HIF- $1 \alpha$ expression. HIF- $1 \alpha$ subunits are regulated primarily at the level of protein stabilization/degradation. Vasseur et $\mathrm{a}^{28}$ previously demonstrated that DJ-1 affected HIF-1 $\alpha$ protein levels in two different cell types (U2OS cells and transformed mouse embryonic fibroblasts [MEFs]). To further explore the functional role of the PI3K/Akt signaling cascade in DJ-1-induced HIF-1 $\alpha$ expression in SW480 cells, we exposed cells to LY294002 or wortmannin, inhibitors of PI3K, and found that both PI3K inhibitors nearly completely blocked DJ-1-induced AKT phosphorylation. However, HIF-1 $\alpha$ expression was partially preserved after treatment with PI3K inhibitors. The present results are consistent with in vivo data showing that the $\mathrm{PI} 3 \mathrm{~K} / \mathrm{Akt}$ pathway-mediated regulation of HIF- $1 \alpha$ is at least partly dependent on DJ-1. Thus, we speculate that the oncogenic properties of DJ-1 are likely due to its influence on the PI3K/Akt/HIF-1 $\alpha$ cell survival pathway. Moreover, it was previously reported that DJ-1 negatively regulates the Von Hippel Lindau (VHL) ubiquitination activity of HIF-1 $\alpha$ by inhibiting the HIF-VHL interaction, whereas the loss of DJ-1 decreased HIF-1 $\alpha$ levels in both hypoxia and oxida- tive stress models. ${ }^{32}$ In contrast, a recent report showed that under normoxic conditions, neuroblastoma cells lacking DJ-1 expression generated hypoxia and ROS that helped to stabilize HIF-1 $\alpha .{ }^{33}$ Therefore, future studies should determine whether the absence of DJ-1 exerts different effects depending on the cell types and experimental systems used.

HIF- $1 \alpha$ mediates the adaptive response to hypoxia via several classical target genes that are involved in angiogenesis (VEGF), apoptosis (BNIP3), and metastasis (PAI-1). ${ }^{34,35}$ Because HIF-1 $\alpha$ transactivates genes that are known to be affected by Akt, we assumed that DJ-1 may modulate some of these genes. Interestingly, all of the HIF-1 $\alpha$ target genes examined in this study were expressed in a DJ-1-dependent manner. Although oxygen-responsive changes include the upregulation of all of these factors ${ }^{36}$ it is clear that HIF- $1 \alpha$ is also activated by DJ-1 under non-hypoxic conditions. VEGF and PAI-1 are markers of prognostic relevance and predictors of early recurrence after curative resection of colon cancer. ${ }^{37,38} \mathrm{BNIP} 3$, a $\mathrm{BH} 3$-containing protein, is a member of the Bcl-2 family of cell death-regulating factors. BNIP3 activates caspase-independent necrosis-like cell death by opening mitochondrial permeability transition pores and may be involved in the pathway that mediates hypoxiainduced necrotic cell death in cancer. ${ }^{39}$ Therefore, to examine whether DJ-1-induced HIF-1 $\alpha$ is required for cell survival, we assessed hypoxia-induced apoptosis in these SW480 and HT-29 cell lines. We found that the rate of apoptosis was lower in SW480/HT-29-DJ-1 ${ }^{+/+}$cells than in SW480/HT$29-\mathrm{DJ}-1^{-/}$and control cells. On the basis of above findings, we suggest that DJ-1-induced HIF- $1 \alpha$ activation regulates many pathways that are advantageous to tumor survival. However, our results also suggest that activating HIF-1 $\alpha$ during cancer evolution also co-selects pathways, such as BNIP3, that can exert potential antitumor effects.

Finally, we examined whether DJ-1 promotes the growth of established tumor xenografts in nude mice. In this study, we observed that while DJ-1-knockdown CRC cells did initially grow, their growth slowed significantly after they attained a certain size, with some tumors even regressing during the latter days of the experiments. As a tumor grows larger, its central core is subjected to hypoxia, and HIF-1 $\alpha$ expression is increased in these areas to promote angiogenesis, growth, survival, and metastasis and to regulate anaerobic glucose metabolism. Thus, our results indicate that HIF-1 $\alpha$ expression is induced by DJ-1 and that DJ-1 enhances hypoxic gene expression to promote tumor growth. As shown in Figure 5, tumor growth was significantly slower after 28 days in the DJ-1-knockdown group than in the DJ-1 overexpression and 
control groups. However, a longer tumor growth period did not improve the clinical relevance of DJ-1 or animal welfare. Thus, only general conclusions can be drawn from the experiments that terminated after 30 days.

In conclusion, this study is the first to document DJ-1 expression in CRC and show that in vivo, DJ-1 is coexpressed with its downstream gene, HIF-1 $\alpha$. Our investigation provides a comprehensive profile of the role of DJ-1 in CRC growth and suggests that the oncogenic properties of DJ-1 are dependent on the unique activation of HIF-1 $\alpha$ and its subsequent transcriptional activity. Because most cancer cells lose the ability to undergo hypoxia-induced cell death, our results indicate that the pathological upregulation of DJ-1 observed in CRC cells is involved in maintaining tumor cell survival.

\section{Conclusion}

Our findings are the first to show that DJ-1 is overexpressed in CRC. We suggest a model in which DJ-1 mediates CRC cell survival by regulating the PI3K/AKT-HIF-1 $\alpha$ pathway.

\section{Acknowledgments}

The authors declare that all data supporting the findings of this study are available within the article and its references. This work was supported by funding from the National Natural Science Foundation of China (NSFC 81400602 to GC and NSFC 81330013 to HY) and the Gut Barrier Research Foundation of Li Jieshou Academician (to YQ). These funding bodies had no role in the design of the study; in the collection, analysis, and interpretation of the data; or in writing the manuscript.

\section{Disclosure}

The authors report no conflicts of interest in this work.

\section{References}

1. Ferlay J, Shin HR, Bray F, Forman D, Mathers C, Parkin DM. Estimates of worldwide burden of cancer in 2008: GLOBOCAN 2008. Int $J$ Cancer. 2010;127(12):2893-2917.

2. Sung JJ, Lau JY, Goh KL, Leung WK. Asia Pacific Working Group on Colorectal C: Increasing incidence of colorectal cancer in Asia: implications for screening. Lancet Oncol. 2005;6(11):871-876.

3. Shehade H, Oldenhove G, Moser M. Hypoxia in the intestine or solid tumors: a beneficial or deleterious alarm signal? Eur J Immunol. 2014;44(9):2550-2557.

4. Semenza GL. Defining the role of hypoxia-inducible factor 1 in cancer biology and therapeutics. Oncogene. 2010;29(5):625-634.

5. Maxwell PH, Wiesener MS, Chang GW, et al. The tumour suppressor protein VHL targets hypoxia-inducible factors for oxygen-dependent proteolysis. Nature. 1999;399(6733):271-275.

6. Keith B, Johnson RS, Simon MC. HIF $1 \alpha$ and HIF $2 \alpha$ : sibling rivalry in hypoxic tumour growth and progression. Nat Rev Cancer. 2011;12(1):9-22.
7. O’Donnell JL, Joyce MR, Shannon AM, Harmey J, Geraghty J, BouchierHayes D. Oncological implications of hypoxia inducible factor-1 alpha (HIF-1alpha) expression. Cancer Treat Rev. 2006;32(6):407-416.

8. Nagakubo D, Taira T, Kitaura H, et al. DJ-1, a novel oncogene which transforms mouse NIH3T3 cells in cooperation with ras. Biochem Biophys Res Commun. 1997;231(2):509-513.

9. Kim RH, Peters M, Jang Y, et al. DJ-1, a novel regulator of the tumor suppressor PTEN. Cancer Cell. 2005;7(3):263-273.

10. Lev N, Ickowicz D, Melamed E, Offen D. Oxidative insults induce DJ-1 upregulation and redistribution: implications for neuroprotection. Neurotoxicology. 2008;29(3):397-405.

11. Zhang HJ, Siu MK, Jiang LL, Mak VC, Ngan HY, Cheung AN. Overexpression of the Parkinson disease protein DJ-1 and its regulator PTEN in gestational trophoblastic disease. Int J Gynecol Pathol. 2010;29(5):468-475.

12. Shi W, Zhang X, Pintilie M, et al. Dysregulated PTEN-PKB and negative receptor status in human breast cancer. Int JCancer. 2003;104(2):195-203.

13. Sheng C, Heng X, Zhang G, et al. DJ-1 deficiency perturbs microtubule dynamics and impairs striatal neurite outgrowth. Neurobiol Aging. 2013;34(2):489-498.

14. Qiu Y, Yu M, Yang Y, et al. Disturbance of intraepithelial lymphocytes in a murine model of acute intestinal ischemia/reperfusion. J Mol Histol. 2014;45(2):217-227.

15. Yang S1, Yu M, Sun L, et al. Interferon- $\gamma$-induced intestinal epithelial barrier dysfunction by NF- $\mathrm{KB} / \mathrm{HIF}-1 \alpha$ pathway. J Interferon Cytokine Res. 2014 Mar;34(3):195-203.

16. Davidson B, Hadar R, Schlossberg A, et al. Expression and clinical role of DJ-1, a negative regulator of PTEN, in ovarian carcinoma. Hum Pathol. 2008;39(1):87-95.

17. Tsuchiya B, Iwaya K, Kohno N, et al. Clinical significance of DJ-1 as a secretory molecule: retrospective study of DJ-1 expression at mRNA and protein levels in ductal carcinoma of the breast. Histopathology. 2012;61(1):69-77.

18. He XY, Liu BY, Yao WY, et al. Serum DJ-1 as a diagnostic marker and prognostic factor for pancreatic cancer. J Dig Dis. 2011;12(2):131-137.

19. Zhu XL, Wang ZF, Lei WB, Zhuang HW, Jiang HY, Wen WP. DJ-1: a novel independent prognostic marker for survival in glottic squamous cell carcinoma. Cancer Sci. 2010;101(5):1320-1325.

20. Yuen HF, Chan YP, Law S, et al. DJ-1 could predict worse prognosis in esophageal squamous cell carcinoma. Cancer Epidemiol Biomarkers Prev. 2008;17(12):3593-3602.

21. Canet-Avilés RM, Wilson MA, Miller DW, et al. The Parkinson's disease protein DJ-1 is neuroprotective due to cysteine-sulfinic acid-driven mitochondrial localization. Proc Natl Acad Sci U SA. 2004;101(24):9103-9108.

22. Zhang L, Shimoji M, Thomas B, et al. Mitochondrial localization of the Parkinson's disease related protein DJ-1: implications for pathogenesis. Hum Mol Genet. 2005;14(14):2063-2073.

23. Xu J, Zhong N, Wang H, et al. The Parkinson's disease-associated DJ-1 protein is a transcriptional co-activator that protects against neuronal apoptosis. Hum Mol Genet. 2005;14(9):1231-1241.

24. He X, Zheng Z, Li J, et al. DJ-1 promotes invasion and metastasis of pancreatic cancer cells by activating SRC/ERK/uPA. Carcinogenesis. 2012;33(3):555-562.

25. Bai J, Guo C, Sun W, et al. DJ-1 may contribute to metastasis of nonsmall cell lung cancer. Mol Biol Rep. 2012;39(3):2697-2703.

26. Bonifati V, Rizzu P, Squitieri F, et al. DJ-1(PARK7), a novel gene for autosomal recessive, early onset parkinsonism. Neurol Sci. 2003;24(3):159-160.

27. Parsanejad M, Zhang Y, Qu D, et al. Regulation of the VHL/HIF-1 Pathway by DJ-1. Journal of Neuroscience. 2014;34(23):8043-8050.

28. Vasseur S, Afzal S, Tardivel-Lacombe J, Park DS, Iovanna JL, Mak TW. DJ-1/PARK7 is an important mediator of hypoxia-induced cellular responses. Proc Natl Acad Sci U S A. 2009;106(4):1111-1116.

29. Zhong H, de Marzo AM, Laughner E, et al. Overexpression of hypoxiainducible factor 1alpha in common human cancers and their metastases. Cancer Res. 1999;59(22):5830-5835. 
30. Belaiba RS, Bonello S, Zähringer C, et al. Hypoxia up-regulates hypoxia-inducible factor-1alpha transcription by involving phosphatidylinositol 3-kinase and nuclear factor kappaB in pulmonary artery smooth muscle cells. Mol Biol Cell. 2007;18(12):4691-4697.

31. Wang C, Fang M, Zhang M, et al. The positive correlation between DJ-1 and $\beta$-catenin expression shows prognostic value for patients with glioma. Neuropathology. 2013;33(6):628-636.

32. Parsanejad M, Zhang Y, Qu D, et al. Regulation of the VHL/HIF-1 pathway by DJ-1. J Neurosci. 2014;34(23):8043-8050.

33. Foti R, Zucchelli S, Biagioli M, et al. Parkinson disease-associated DJ-1 is required for the expression of the glial cell line-derived neurotrophic factor receptor RET in human neuroblastoma cells. J Biol Chem. 2010;285(24):18565-18574.

34. Schaible EV, Windschügl J, Bobkiewicz W, et al. 2-Methoxyestradiol confers neuroprotection and inhibits a maladaptive HIF- $1 \alpha$ response after traumatic brain injury in mice. J Neurochem. 2014;129(6): 940-954.
35. Azad MB, Chen Y, Henson ES, et al. Hypoxia induces autophagic cell death in apoptosis-competent cells through a mechanism involving BNIP3. Autophagy. 2008;4(2):195-204.

36. Ergorul C, Ray A, Huang W, et al. Hypoxia inducible factor- $1 \alpha(\mathrm{HIF}-1 \alpha)$ and some HIF-1 target genes are elevated in experimental glaucoma. $J$ Mol Neurosci. 2010;42(2):183-191.

37. Min BS, Kim NK, Jeong HC, Chung HC. High levels of serum VEGF and TIMP-1 are correlated with colon cancer liver metastasis and intrahepatic recurrence after liver resection. Oncol Lett. 2012;4(1): 123-130.

38. Märkl B, Renk I, Oruzio DV, et al. Tumour budding, uPA and PAI-1 are associated with aggressive behaviour in colon cancer. J Surg Oncol. 2010;102(3):235-241.

39. vande Velde C, Cizeau J, Dubik D, et al. BNIP3 and genetic control of necrosis-like cell death through the mitochondrial permeability transition pore. Mol Cell Biol. 2000;20(15):5454-5468. 


\section{Supplementary materials}

A

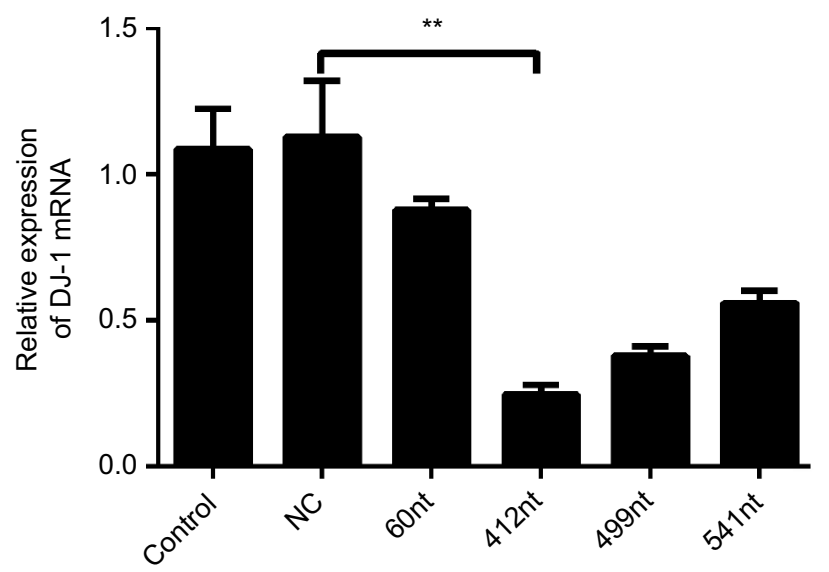

SW480

Control NC 60nt 412nt 499nt 541nt

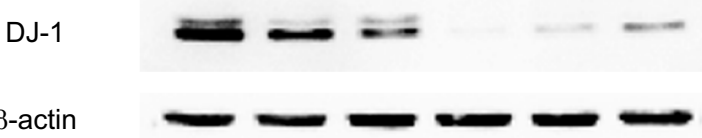

C

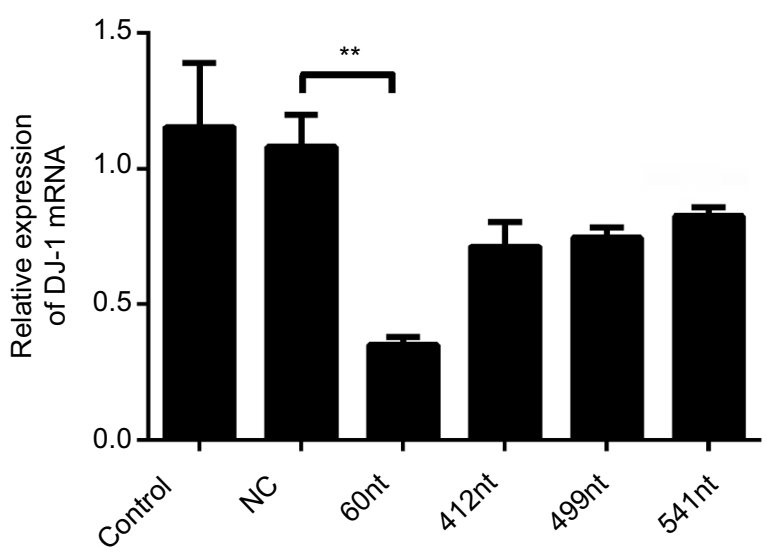

HT-29

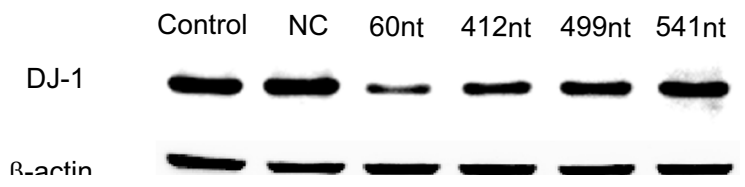

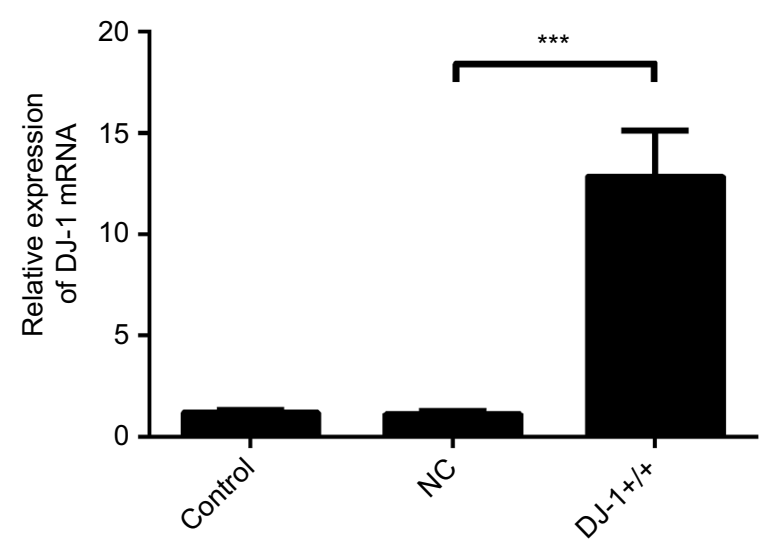

SW480

Control NC DJ-1+/+

DJ-1

$\beta$-actin

D

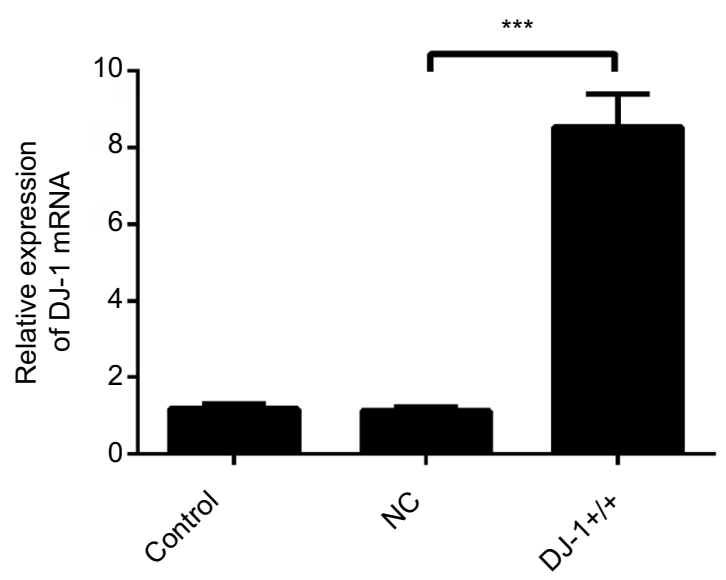

HT-29

Control NC DJ-1+/+

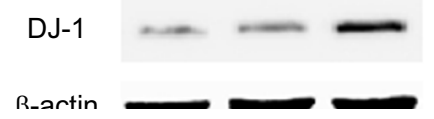

Figure SI Establishment of DJ-I stable overexpression and knockdown colon cancer cells.

Notes: (A, B) DJ-I mRNA levels and corresponding protein immunoblots in parental SW480/HT-29, SW480/HT-29 NC-shRNA, and SW480/HT-29 DJ-I-shRNA (SW480/ HT-29-DJ- $-^{--1}$ ) cells. (C, D) DJ-I mRNA levels and corresponding protein immunoblots in parental SW480/HT-29, SW480/HT-29 vector (NC), and SW480/HT-29 DJ-Ioverexpression (SW480/HT-29-DJ-I ${ }^{+/+}$) cells. The results are expressed as the ratio of the number of copies of the gene of interest to the number of copies of the $\beta$-actin gene. The results shown are representative of three experiments. $* * P<0.01, * * * P<0.001$.

Abbreviation: NC, negative control. 
Cancer Management and Research

\section{Publish your work in this journal}

Cancer Management and Research is an international, peer-reviewed open access journal focusing on cancer research and the optimal use of preventative and integrated treatment interventions to achieve improved outcomes, enhanced survival and quality of life for the cancer patient.

The manuscript management system is completely online and includes

Submit your manuscript here: https://www.dovepress.com/cancer-management-and-research-journal 